\title{
Use of copper slag as a replacement for fine aggregate in reinforced concrete slender columns
}

\author{
A. S. Alnuaimi \\ Department of Civil and Architectural Engineering, \\ Sultan Qaboos University, Oman
}

\begin{abstract}
The use of copper slag as a replacement for fine aggregate in construction will reduce damage to the environment due to the waste resulting from the copper manufacturing process and help in saving natural resources. In this research, the use of copper slag as a replacement for fine aggregate is investigated. Three slender reinforced concrete columns of $150 \times 150 \times 2500 \mathrm{~mm}$ were tested for monotonic axial compression load until failure. The concrete mix included ordinary Portland cement, fine aggregate, $10 \mathrm{~mm}$ coarse aggregate and copper slag. The ratios of copper slag to fine aggregate were $0 \%, 40 \%$ and $80 \%$. Four- $8 \mathrm{~mm}$ diameter high yield steel bars were used as longitudinal reinforcement and $6 \mathrm{~mm}$ diameter mild steel bars were used as stirrups. Three cubes, $100 \times 100 \times 100 \mathrm{~mm}$, three cylinders, $150 \times 300 \mathrm{~mm}$, and three prisms, $100 \times 100 \times 500 \mathrm{~mm}$, were cast from the same mix of each specimen at the same time. Curing for the specimen and the samples was carried out using wet Hessian cloths for one week and then they were left under room temperature for about five weeks. Test results were judged by longitudinal steel strain, lateral displacement and failure load. The test results so far showed that up to $40 \%$ replacement of fine aggregate by copper slag does not have a significant effect on the load carrying capacity of the columns. Increasing the copper slag beyond this ratio accelerates the buckling, which leads to premature (before steel yields) failure load and a larger deflection.
\end{abstract}

Keywords: copper slag, fine aggregate, column, axial load, cylinder column. 


\section{Introduction}

Aggregate is the main constituent of concrete, since it occupies more than $70 \%$ of the concrete matrix. In many countries there is a scarcity of natural aggregate that is suitable for construction, whereas in other countries the consumption of aggregate has been increased, in recent years, due to the increase in the construction industry. In order to reduce dependence on natural aggregate in construction, artificially manufactured aggregate and some industrial waste material can be used as an alternative. Since the beginning of the industrial revolution, slag, glassy materials and left over material when metals have been extracted from ores have been considered as waste. One such material is the copper slag that is produced during matte smelting and converting steps (Al-Jabri [1]).

Processed air-cooled and granulated copper slag has a number of favourable mechanical properties for aggregate use, including excellent soundness characteristics and good abrasion resistance. Some of the properties of copper slag are favourable for use as aggregate in asphalt paving applications (Queneau et al. [2]). The copper slag is generally similar to sand as far as maximum, minimum and average void ratios are concerned. The angle of friction of shearing resistance of the slag is generally higher than that of sands. This is because of angularity of the slag particles. Utilization of copper slag for applications such as a replacement for fine aggregate in concrete has the dual benefit of eliminating the costs of disposal, and lowering the cost of the concrete.

It appears that the slag can be used as a fill material; of course, slight variations in prosperities of the slag may be anticipated depending on the source (Das et al. [3]).

It has been estimated that for every ton of copper production about 2.2 ton of slag is generated and slag containing less than $0.8 \%$ copper is either discarded as waste or sold as a cheap product. Dumping or disposal of the copper slag causes environmental problems. Therefore, its use was explored by several investigators and they have utilized the slag in diversified ways, including the recovery of metal values and the preparation of value added products, such as cement, cement replacement in concrete, fill, ballast, abrasive, aggregate, glass, tiles etc (Shi and Meyer [4]).

Shoya et al [5] found no major differences in concrete compressive strength due the use of cooper slag as a replacement for fine aggregate. Resende et al. [6] reported a small reduction in concrete compressive and flexural strengths due to substitution of natural sand by copper slag. Workability was also reduced, although it stayed within reasonable limits.

Research is going on at Civil and Architectural Engineering Department, Sultan Qaboos University, to investigate the effect of partial and full replacement of fine aggregate with copper slag on the strength and behaviour of slender reinforced concrete columns. The column has a $150 \times 150 \mathrm{~mm}$ cross section and a length of $2500 \mathrm{~mm}$. The results found so far are presented in this paper. 


\section{Material used}

Ordinary Portland cement (OPC), purchased from the Oman Cement Company, and natural fine and $10 \mathrm{~mm}$ coarse aggregates, purchased from a nearby crusher in the Al-Khoudh area, were used in this research. The copper slag was bought from the Oman Mining Company, which produces an average of 60,000 tons annually (Taha et al. [7]). Four $8 \mathrm{~mm}$ diameter high yield bars were used as longitudinal reinforcement and $6 \mathrm{~mm}$ diameter mild steel bars were use as stirrups with spacing of $150 \mathrm{~mm}$. Samples of three cubes of $150 \times 150 \times 150 \mathrm{~mm}$, three cylinders of $150 \times 300 \mathrm{~mm}$ and three prisms of $100 \times 100 \times 500 \mathrm{~mm}$ were cast simultaneously with the specimen from the same mix. The samples were used to test the compressive and tensile strengths of the concrete. Table 1 shows the batch quantities of the mixes used for the three columns tested.

Table 1: Batch quantities.

\begin{tabular}{|c|c|c|c|c|c|}
\hline $\begin{array}{c}\text { Column } \\
\text { No. }\end{array}$ & $\begin{array}{c}\text { Water } \\
(\mathrm{kg})\end{array}$ & $\begin{array}{c}\text { Cement } \\
(\mathrm{kg})\end{array}$ & $\begin{array}{c}10 \mathrm{~mm} \\
\text { Aggregate }(\mathrm{kg})\end{array}$ & $\begin{array}{c}\text { Fine } \\
\text { aggregate }(\mathrm{kg})\end{array}$ & $\begin{array}{c}\text { Copper } \\
\text { slag }(\mathrm{kg})\end{array}$ \\
\hline $0 \% \mathrm{CS}$ & 30.8 & 52.2 & 154.3 & 96.8 & 0 \\
\hline $40 \% \mathrm{CS}$ & 30.8 & 52.2 & 154.3 & 58.08 & 38.72 \\
\hline $80 \% \mathrm{CS}$ & 30.8 & 52.2 & 154.3 & 19.36 & 77.44 \\
\hline
\end{tabular}

\section{Instrumentation and casting}

Fig. 1 shows the steel strain gauges' labelling method. For each longitudinal bar, two strain gauges (A, B) were stuck opposite each other at the mid-span of the column. The letter (L) was used to identify the location of strain gauge, i.e. L2A means the number of the strain gauge that is stuck on longitudinal bar number 2 at location A. Two stirrups, one below and one above the mid-span of the column by $75 \mathrm{~mm}$, were strain gauged. Four strain gauges were stuck on each stirrup, one on each face of the column. The letters $\mathrm{S}$ and $\mathrm{B} / \mathrm{T}$ were used to differentiate between the strain gauges, i.e. ST1 means the number of the gauge in the upper stirrup on face 1 of the column and SB4 means the gauge that is in the lower stirrup at face 4 of the column. To measure lateral deflection of the beam, a linear variable differential transducer LVDT was installed on each face at the mid-span of the column (Fig. 2). The concrete surface strain was measured using $100 \mathrm{~mm}$ horizontal and $200 \mathrm{~mm}$ vertical DEMEC gauges at mid-span.

After installing the steel strain gauges, the steel cage was prepared and inserted into a wooden mould. The strain gauges were numbered and casting of the specimen and the samples was carried out. 


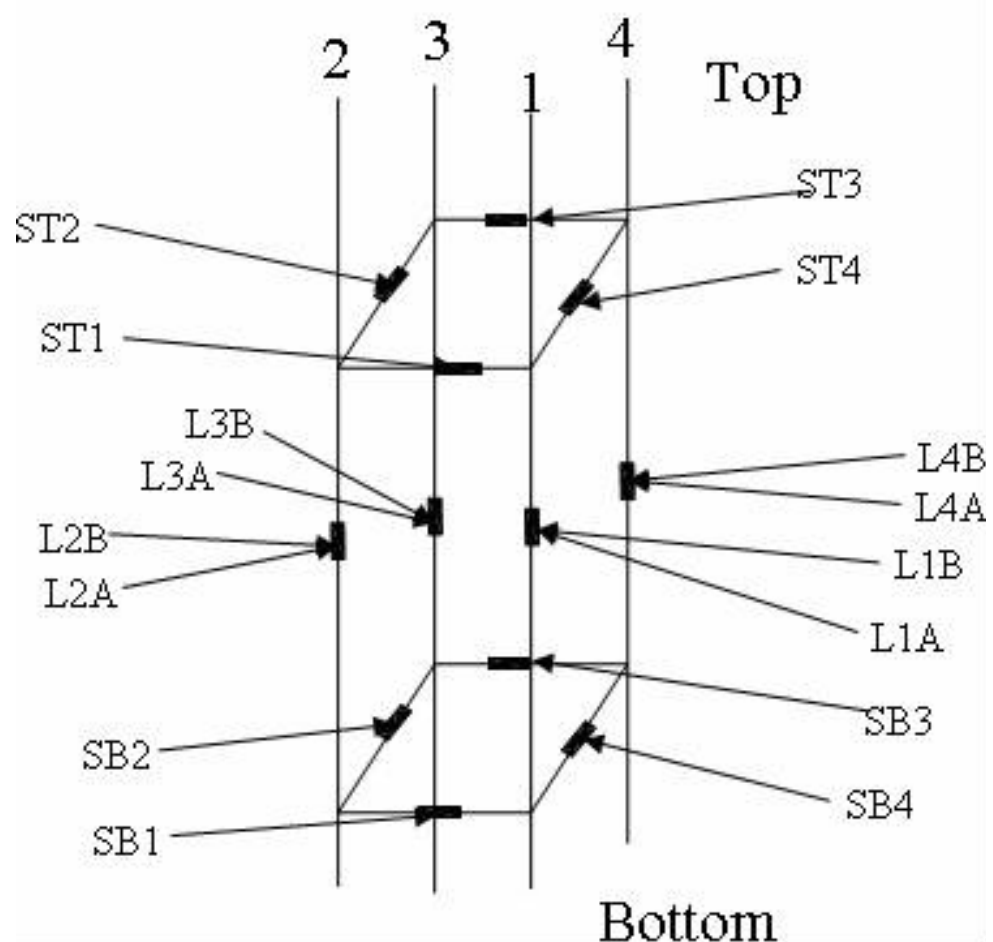

Figure 1: $\quad$ System of labelling the strain gauges.

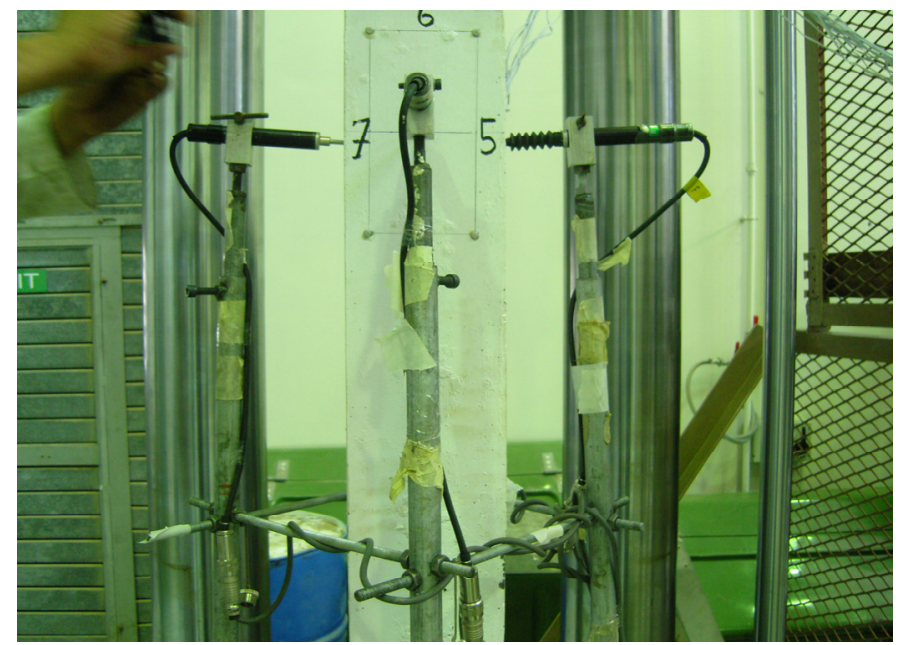

Figure 2: $\quad$ LVDT on each face at mid-span of the column. 


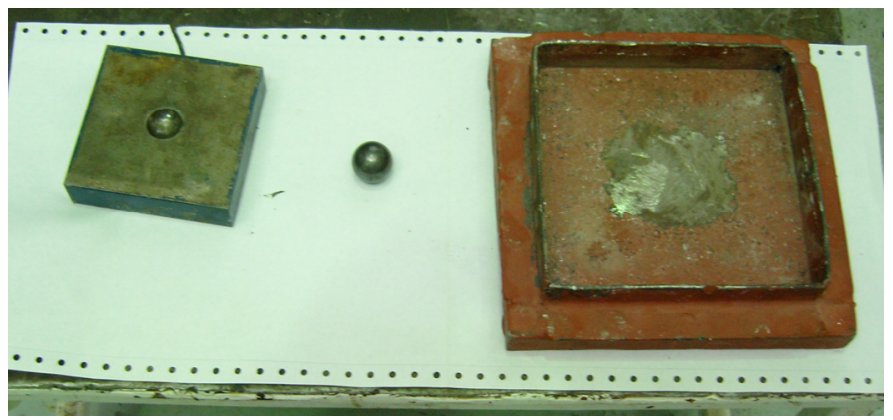

Figure 3: $\quad$ Base plate, ball and cap used at the bottom and top ends of the column.

Table 2: $\quad$ Average material properties.

\begin{tabular}{|c|c|c|c|c|c|c|}
\hline $\begin{array}{c}\text { Column } \\
\text { No. }\end{array}$ & $\begin{array}{c}\mathrm{f}_{\mathrm{cu}} \\
\left(\mathrm{N} / \mathrm{mm}^{2}\right)\end{array}$ & $\begin{array}{c}\mathrm{f}_{{ }_{\mathrm{c}}} \\
\left(\mathrm{N} / \mathrm{mm}^{2}\right)\end{array}$ & $\begin{array}{c}\mathrm{f}_{{ }_{\mathrm{t}}} \\
\left(\mathrm{N} / \mathrm{mm}^{2}\right)\end{array}$ & $\begin{array}{c}\mathrm{f}_{\mathrm{r}} \\
\left(\mathrm{N} / \mathrm{mm}^{2}\right)\end{array}$ & $\begin{array}{c}\mathrm{f}_{\mathrm{y}} \\
\left(\mathrm{N} / \mathrm{mm}^{2}\right)\end{array}$ & $\begin{array}{c}\mathrm{f}_{\mathrm{yv}} \\
\left(\mathrm{N} / \mathrm{mm}^{2}\right)\end{array}$ \\
\hline $0 \%$ CS & 34.4 & 27.0 & 3.2 & 4.9 & 580 & 250 \\
\hline $40 \%$ CS & 33.9 & 26.3 & 2.9 & 4.3 & 580 & 250 \\
\hline $80 \%$ CS & 31.3 & 25.8 & 2.7 & 4.0 & 580 & 250 \\
\hline Average & 33.2 & 26.37 & 2.93 & 4.4 & 580 & 250 \\
\hline
\end{tabular}

\section{Testing and results}

After curing under wet Hessian cloths for one week, the specimen and the samples were left under room temperature for about four weeks before testing. The column was painted white and the DEMEC pins were fixed. The column was installed on a $5000 \mathrm{kN}$ DARTEC universal testing machine using a steel plate cap and a steel ball at each end to ensure the application of compressive axial load alone. Fig. 3 shows the cap and ball system used while Fig. 4 shows a typical column installed on a testing machine. The load was applied in increments of $50 \mathrm{kN}$ for the first three increments followed by reduced increments of $20 \mathrm{kN}$ until $210 \mathrm{kN}$ was reached and then by $10 \mathrm{kN}$ increments until failure. To allow for stable deformation to take place after each load increment, an interval of about one minute was used before recording the readings. The strain gauges and LVDTs were connected to a data logger while the DEMEC readings were taken manually. The cube, cylinder and prism samples were tested on the same day that the column was tested.

Table 2 shows the average cube and cylinder compressive strengths, the average cylinder splitting and prism flexural tensile strengths. It also gives the average yield strength of the reinforcement used. It is clear that a minor reduction in the concrete compressive and tensile strengths was reported due to the increase of the ratios of copper slag to fine aggregate. 


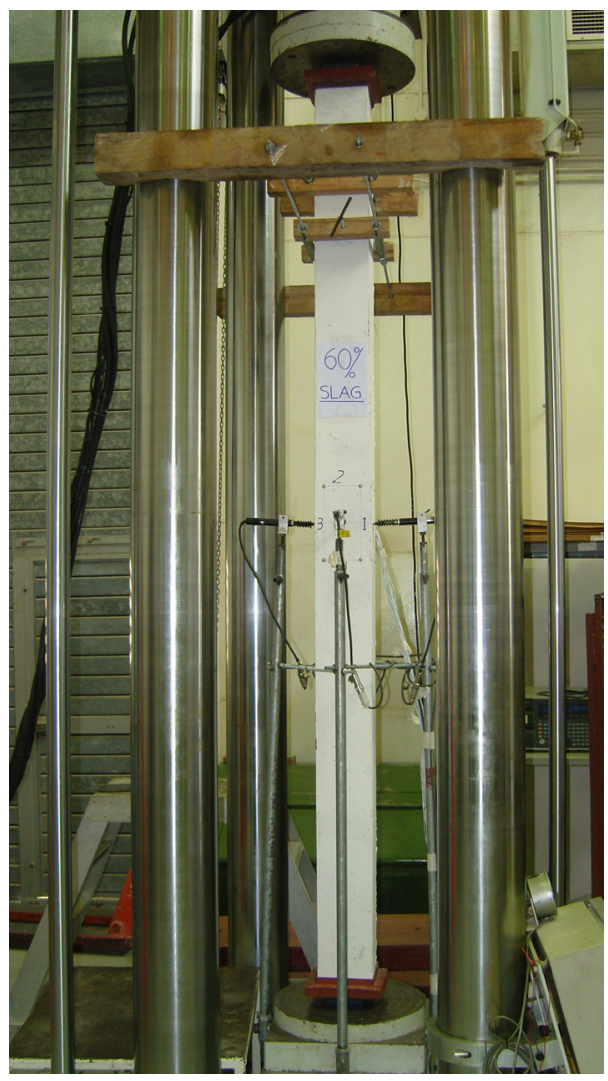

Figure 4: Typical column installed on the $5000 \mathrm{kN}$ DARTEC testing machine.

Table 3: $\quad$ Failure loads of the columns.

\begin{tabular}{|c|c|c|}
\hline Column No & Failure Load $(\mathrm{kN})$ & L.F. Ratio \\
\hline $0 \% \mathrm{CS}$ & 552 & 0.97 \\
\hline $40 \% \mathrm{CS}$ & 629 & 1.1 \\
\hline $80 \% \mathrm{CS}$ & 472.1 & 0.83 \\
\hline
\end{tabular}

\subsection{Failure load}

Table 3 shows the measured failure loads and the ratio of measured failure load to design load L.F. It is clear that the presence of up to $40 \%$ copper slag as a replacement for fine aggregate has resulted in some increase in the load carrying capacity. However, a high percentage of copper slag $(80 \%)$ resulted in reduction 
in the failure load of up to $17 \%$. It was noticed during testing that a large presence of copper slag resulted in earlier buckling of the column, which led to earlier failure load than when the percentage of copper slag was low. The failure of the $0 \%$ CS column was more sudden with less time between the start of buckling and failure than columns with $40 \%$ and $80 \% \mathrm{CS}$.

\subsection{Steel strain}

Fig. 5 shows the ratio of the measured to yield longitudinal steel strain $\varepsilon / \varepsilon_{\mathrm{y}}$ versus the measured load to design load ratios L.F. It is clear that as the percentage of copper slag increases the column stiffness decreases (more strain for same load). In spite of the lower load resisted, the steel strain in the $80 \% \mathrm{CS}$ column reached near yield strain while less strain were recorded in the $0 \% \mathrm{CS}$ $\left(\varepsilon / \varepsilon_{\mathrm{y}}=48 \%\right)$ and $40 \% \mathrm{CS}\left(\varepsilon / \varepsilon_{\mathrm{y}}=70 \%\right)$ before failure.

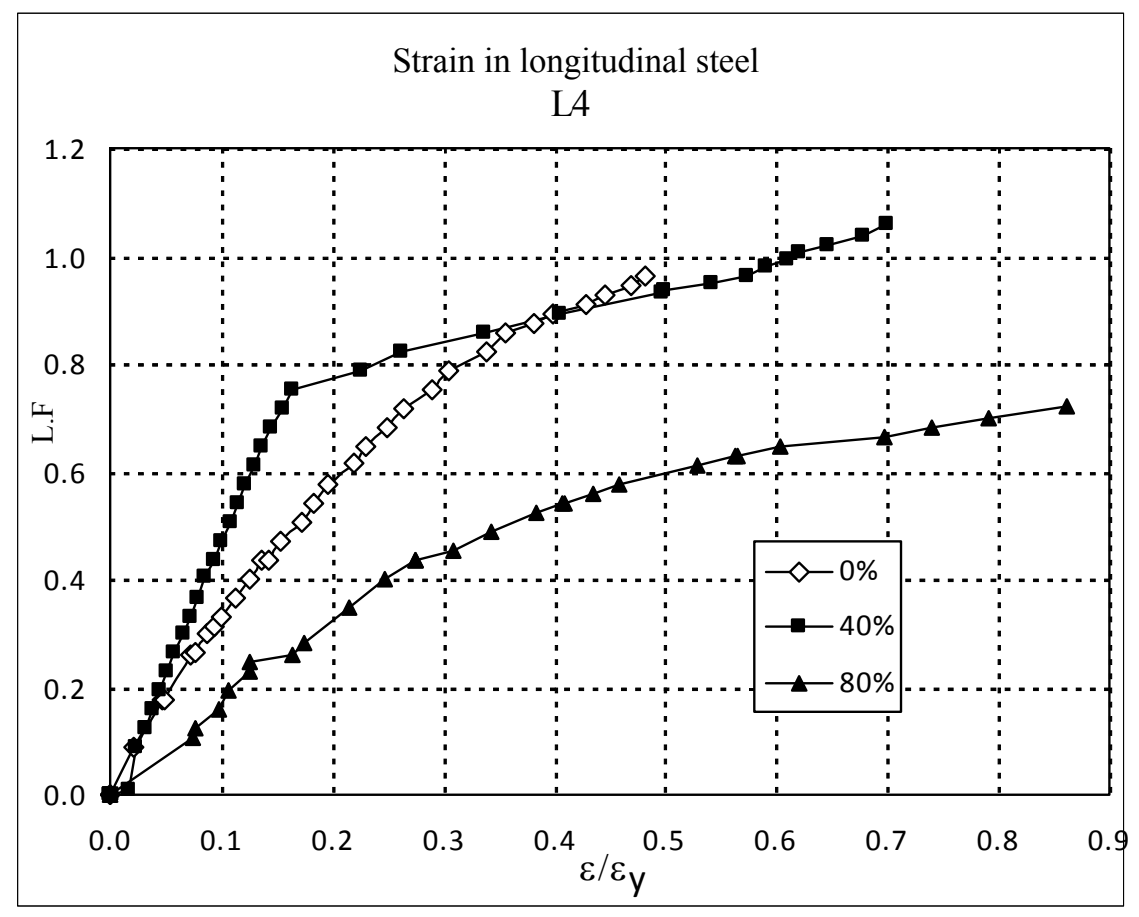

Figure 5: $\quad$ Strain in the longitudinal bars.

\subsection{Lateral deflection}

Table 4 shows the maximum measured displacement values in the four faces of the three columns with different copper slag to fine aggregate ratios. The positive values indicate extension. It should be mentioned that, for the purpose of safety, the LVDT readers were removed immediately after the signs of buckling, which 
means some readings were not recorded. Fig. 6 shows a typical load versus displacement trend in the tested columns. It is clear that there were no major differences in deflection values between $0 \% \mathrm{CS}$ and $40 \% \mathrm{CS}$ while the $80 \% \mathrm{CS}$ column recorded much more displacement. This indicates that the high percentage of copper slag leads to more ductile behaviour.

Table 4: $\quad$ Effect of copper slag on lateral displacements.

\begin{tabular}{|c|c|c|c|c|}
\hline Column & $\begin{array}{c}\text { Front face } \\
\text { Disp. }(\mathrm{mm})\end{array}$ & $\begin{array}{c}\text { Rear face } \\
\text { Disp. (mm) }\end{array}$ & $\begin{array}{c}\text { Right face } \\
\text { Disp. (mm) }\end{array}$ & $\begin{array}{c}\text { Left face } \\
\text { Disp. (mm) }\end{array}$ \\
\hline $0 \% \mathrm{CS}$ & -2.3 & 2.2 & -0.1 & 0.2 \\
\hline $40 \% \mathrm{Cs}$ & -2.7 & 2.7 & -0.92 & 1.05 \\
\hline $80 \% \mathrm{CS}$ & -10.2 & 9.8 & -1.4 & 1.65 \\
\hline
\end{tabular}

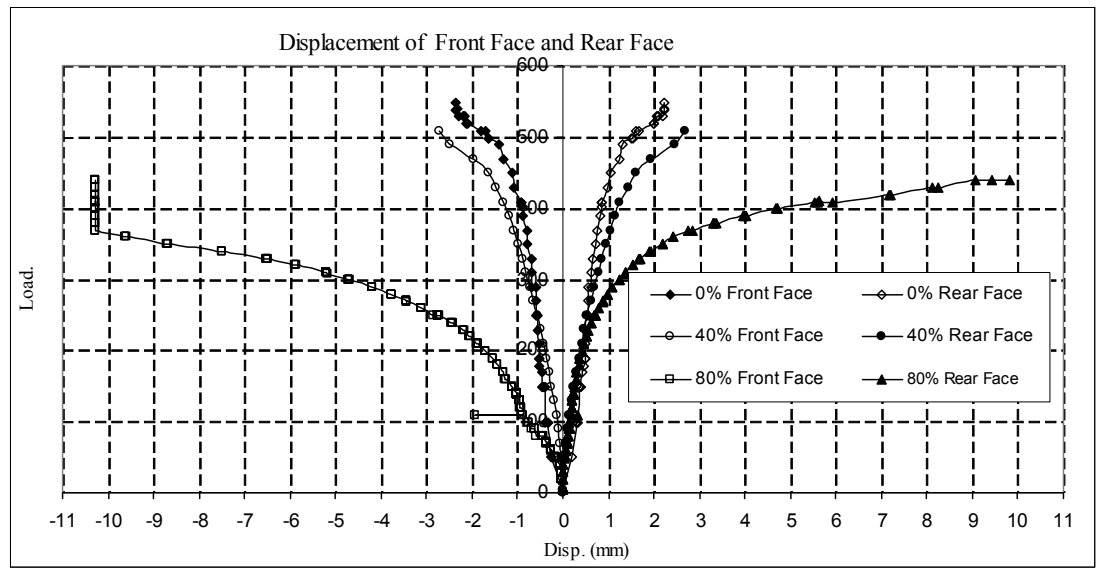

Figure 6: Typical lateral deflection in the tested columns.

\section{Conclusions and recommendations}

The use of copper slag as a replacement for fine aggregate is environmentally helpful due to the reduction in the waste produced from the copper manufacturing process and saving the natural fine aggregate. The results collected so far showed that increasing the ratio of copper slag as a replacement for fine aggregate reduces the column failure load and increases deflection. The difference was more pronounced in the $80 \%$ CS column. The steel in this column (80\% CS) reached near yield strain, while other columns experienced lower strain ratios, which indicates that a larger load was carried by the reinforcement than the concrete in the case of $80 \%$ CS. Further study on the effect of copper slag on concrete strength, as well as structural behaviour, is needed. At Sultan 
Qaboos University, tests on the concrete strengths and slender columns' behaviour, which have different percentages of copper slag as a replacement for fine aggregate, are in full swing.

\section{References}

[1] Al Jabri K.S. Copper Slag as Fine Aggregate for High Performance Concrete, WIT Transaction on the Built Environment, WIT-Press, High Performance Structures and Materials III, v85, pp. 381- 389, 2006.

[2] Queneau P. B., Cregar D. E. and May L. D. Application of Slag Technology to Recycling of Solid Wastes, SME Annual Meeting, Denver, CO, USA, 02/25-28/91, 1991.

[3] Das B. M., Tarquin A. J. and Jones A. Q. Geotechnical Properties of Copper Slag, Transportation Research Record No. 941, pp. 1 - 4, 1983.

[4] Shi C., Meyer C. and Behnood A. Utilization of copper slag in cement and concrete, Resources, Conservation and Recycling, v52, pp. 1115 - 1120, 2008.

[5] Shoya M., Sugita S., Tsukinaga Y., Aba M. and Tokubasi K. Properties of self-compacting concrete with slag fine aggregates, Exploiting Wastes in Concrete, 1999

[6] Resende C., Cachim P. and Bastos A. Copper slag mortar properties, Material Science Forum, Trans Tech Publications, v587 - 588, pp. 862 866, 2008.

[7] Taha R. A., Alnuaimi A. S., Al-Jabri K. S., and Al-Harthy A.S. Evaluation of controlled low strength material containing industrial by-product, Building and Environment, v 42, pp. 3366 - 3372, 2007. 